\title{
SPILLOVER EFFECTS OF EXCHANGE RATE RETURNS IN SELECTED ASIAN COUNTRIES
}

\author{
Neluka Devpura \\ University of Sri Jayewardenepura, Faculty of Applied Sciences, Department of Statistics, Sri Lanka. \\ Email: ndevpura@sci.sjp.ac.lk
}

\begin{abstract}
We analyze the nature of exchange rate return spillovers for 16 currencies. We use 10 years of daily exchange rate data, covering January 01, 2010 to December 31, 2019. By using the spillover index proposed by Diebold and Yilmaz $(2009,2012)$, we provide empirical evidence on the spillover of exchange rate returns among the Asian countries. The largest spillover flows from the Singapore dollar to other currencies (16.49\%). Overall, our results confirm the presence of exchange rate return spillovers within the Asian countries and about $22 \%$ of the forecast error variance is due to spillovers.
\end{abstract}

Keywords: Exchange rates; Spillover effects; Spillover index.

JEL Classifications: C40; G20; F020.

\section{Article history:}

Received : March 25, 2020

Revised : June 23, 2020

Accepted : November 27, 2020

Available online : March 31, 2021

https://doi.org/10.21098/bemp.v24i1.1301 


\section{INTRODUCTION}

One of the key tasks of central banks is to stabilize the exchange rate to manage the country's economy. Therefore, it is of interest to examine how exchange rates can be influenced by information. Spillover is a process of informational transmission and we investigate spillover effects in exchange rates, specifically in the Asian region. One main mode of transmission or spillover is through the volatility or variance. The computation of volatility is basically done using price returns data. Hence, returns and volatility of returns have become main spillover variables in the literature.

The purpose of this paper is to investigate whether exchange rate return spillovers exist among Asian currencies. A voluminous literature examines the return/volatility spillover from one asset class to other asset classes (foreign exchange, stock, bond, and commodity markets, for instance), cross-country or regions. ${ }^{1}$ The motivation for our investigation has roots in the work of Diebold and Yilmaz (2009), who examine the return spillovers and volatility spillovers of seven developed and twelve emerging markets. ${ }^{2}$ They propose a new spillover index using the Vector Autoregression (VAR) model and they find opposing behaviour in the dynamics of return and volatility spillovers. In addition, Diebold and Yilmaz (2012) examine volatility spillovers across different asset classes; namely, the US stock, bond, foreign exchange and commodities markets based on daily data. Their main finding is that cross-market volatility spillovers exist but is limited until 2007. A recent paper by Chow (2017) investigates volatility spillover of the US, the UK and 10 emerging markets. Nguyen and Le (2018) examine return spillover from the US and Japanese stock markets to the Vietnamese stock market using daily data. They find return spillover from the US to the Vietnamese stock market and also from the Japanese to the Vietnamese stock market.

Our focus in this paper belongs to the literature on exchange rate returns spillover. Though, there are several studies on volatility spillovers, comparative analysis of spillovers among exchange rates is limited. In this research, we use the US dollar as the base currency because the US dollar is the major and most widely used international currency. Our approach can be summarized in three steps.

First, we use 16 exchange rates from the Asian countries. These are the Bangladesh Taka (BDT), Chinese yuan (CNH), Hongkong dollar (HKD), Indonesia rupiah (IND), India rupee (INR), Japanese yen (JPY), Nepal rupee (NPR), Malaysia ringgit (RING), Pakistan rupee (PKR), Philippine Peso (PHP), Sri Lanka rupee (LKR), Singapore dollar (SGD), South Korea won (KOR), Taiwan dollar (TDO), Thailand baht (BAHT), and Vietnamese Dong (VND).

\footnotetext{
Al-Deehani and Moos (2006) investigate volatility spillovers among three emerging stock markets of Bahrain, Kuwait, and Saudi Arabia. Their results indicate volatility spillovers exist and the Kuwait market is the most influential market among the three markets. Kim and Ryu (2015) examine return spillover and volatility transmission between the U.S. and Korean stock markets and conclude that there is significant volatility transmission between these two markets. Fukuda and Tanaka (2017) explore the spillovers from the Asian financial market. Baele (2005) explores volatility spillover effects from aggregate European Union and the US to 13 European equity markets,

2 The seven developed stock markets are the US, the UK, France, Germany, Hong Kong, Japan and Australia and twelve emerging markets are Indonesia, South Korea, Malaysia, the Philippines, Singapore, Taiwan, Thailand, Argentina, Brazil, Chile, Mexico and Turkey.
} 
Second, we convert the rates to returns covering the sample January 01, 2010 to December 31, 2019, which allows us to capture any evidence of spillovers over time. Third, we use the spillover index proposed by Diebold and Yilmaz (2009, 2012). They propose a generalized decomposition of variance from a VAR model. The principal innovation of Diebold and Yilmaz (2012) is the use of generalised impulse responses rather than conventional Cholesky shocks (see, Diebold and Yilmaz, 2009). We also construct a spillover index, which summarizes the total extent of the spillovers in a single measure.

Our approach contributes two fresh insights on exchange rate return spillovers. The first main finding is that Asian currencies are characterized by return spillovers: that is, about $22 \%$ of the forecast error variance results from spillovers. This implies that exchange rate shocks are important. The second finding is that the largest spillover is coming from the Singapore dollar to the other currencies $(16.49 \%)$. Singapore ranks in the world's top-five as a financial center and operates with a free-market economy. Moreover, Singapore's monetary policy is centered on the exchange rate and it maintains strong price stability. The country is considered to be the financial hub in Asia and from our analysis implies that shocks to Singapore's currency is of importance to the rest of Asia.

Our approach and results contribute to the extension of the spillover literature; see McMillan and Speigh (2010) for exchange return spillover; for volatility of exchange rates spillover, see Couderta, Couhardeb, and Mignon (2011) and Bubak, Kocenda, and Zikes (2011); and for high frequency data of exchange rate return spillover, see Baillie and Bollerslev (1991) and Kitamura (2010). ${ }^{3}$ Our contribution is to show the importance of exchange rate shocks in the Asian context. This is not a trivial matter. An investigation of the spillover relationships among Asian exchange rates is beneficial for market participants and investors. The exchange rate spillover and interdependence of the exchange rates may predict the future movement of each other effectively. Also, there are implications for portfolio managers. The spillover effects, particularly the information that spillovers result from the Singapore dollar, can be factored into portfolio diversification strategies.

The remainder of this paper proceeds as follows. Section II describes the methodology and Section III presents data. Section IV presents empirical results. Finally, we present concluding remarks in Section V.

\section{METHODOLOGY}

Our main objective is to measure the exchange rate returns spillover among 16 Asian currencies by using the Diebold and Yilmaz (2009, 2012). In this section, we describe the spillover index proposed by Diebold and Yilmaz $(2009,2012)$. The

\footnotetext{
3 McMillan and Speight (2010) using the US dollar, the Japanese yen and the British pound conclude that the dollar rate dominates the other two rates in terms of both return and volatility spillovers. Couderta, Couhardeb, and Mignon (2011) examine the volatility spillover of exchange rates from 21 emerging countries. They confirm that exchange rate volatility increase with the global financial stress, for most of these emerging countries. Bubak, Kocenda, and Zikes (2011) study the dynamics of volatility transmission between Central European currencies and the Euro to US dollar foreign exchange and find statistically significant volatility spillovers among the Central European foreign exchange markets.
} 
initial spillover index is computed from a variance decomposition associated with an $N$-variable VAR. The idea behind this is that the variance decompositions spilt the forecast error variances of each variable into different system shocks. Finally, they aggregate these values and come up with a single value called spillover index. There are a number of drawbacks in the spillover index proposed by Diebold and Yilmaz (2009). First, the use of Cholesky-factor identification of VARs results in variance decompositions that are dependent on the order of the variables. Second, although, Diebold and Yilmaz (2009) extract the total spillover index, they have been unable to identify directional spillovers. Thus, as an improvement of the spillover index, Diebold and Yilmaz (2012) use the generalised impulse response functions to overcome the issue of variable ordering. They also construct the directional spillovers. They further define two types of variances; namely, own variance shares (that is the part of the variances from h-step ahead error in forecasting due to $y_{t}$ shocks) and cross variance shares (known as spillovers).

Consider a covariance stationary $N$-variable $\operatorname{VAR}(p)$,

$$
y_{i}=\sum_{i=1}^{p} y_{i-1}+v_{i}
$$

Where $v_{i} \sim(0, \Sigma)$ are the errors distributed i.i.d with variance matrix, denoted as $\Sigma$. In our case, $N$ is the number of currencies, which is sixteen.

Let $\theta_{i j}$ denote the generalized $h$-step ahead forecast error variance decompositions (the two types of variances; 1 ) own variance shares forecasting $y_{i}$ due to shocks to $y_{i}$ for $i=1 \cdots N$ and 2 ) cross variance shares as forecasting $y_{i}$ from shocks $y_{j}$, for $\left.j=1 \cdots N,(i \neq j)\right)$.

$$
\theta_{i j}=\frac{\sum_{k=0}^{h-1}\left(e_{i}^{\prime} A_{k} \Sigma e_{j}\right)^{2}}{\sigma_{i i} \sum_{k=0}^{h-1}\left(e_{i}^{\prime} A_{k} \Sigma A_{i}^{\prime}\right)}
$$

Where $\Sigma$ and $\sigma_{i i}$ are the variance matrix and standard deviation of errors. $e_{i}$ is the selection vector of which 1 as the $i$-th value and the rest are zeros.

The total spillover index is denoted as $S$ and constructed as below;

$$
S=\frac{\sum_{\substack{i, j=1 \\ i \neq j}}^{N} \theta_{i j}^{h}}{\sum_{i, j=1}^{N} \theta_{i j}^{h}} * 100
$$

where $\theta_{i j}^{h}=\frac{\theta_{i j}}{\sum_{j=1}^{N} \theta_{i j}}$. 


\section{A. Directional Spillover Measures}

In addition to the spillover index, Diebold and Yilmaz (2012) also construct directional spillovers across from different asset classes. There are two directional spillovers introduced and they are known as from and to. The directional spillovers enable us to know how much shock is transmitted from and to the markets. The directional spillovers received by market $i$ from all other markets $j$ are:

$$
S_{i .}=\frac{\sum_{\substack{j=1 \\ i \neq j}}^{N} \theta_{i j}^{h}}{\sum_{j=1}^{N} \theta_{i j}^{h}} * 100
$$

The directional spillovers transmitted by market $i$ to all other markets $j$ are:

$$
S_{. i}=\frac{\sum_{\substack{j=1 \\ i \neq j}}^{N} \theta_{j i}^{h}}{\sum_{j=1}^{N} \theta_{j i}^{h}} * 100
$$

\section{B. Net Spillover}

Finally, the net volatility (return) spillover can be computed as the difference between gross volatility (return) shocks transmitted to and received from all other exchange rate returns. Let us denote this by $S_{i}$ and calculate as;

$$
S_{i}=S_{i .}-S_{. i}
$$

The net volatility/return spillover shows the summarized information about how much in net terms each exchange rate contributes to volatility/returns in other exchange rates.

\section{DATA}

The dataset is daily and covers January 01, 2010 to December 31, 2019. All the data are downloaded from Datastream.

Table 1 shows the details of all the 16 currencies that we have considered for our analysis. Column two indicates the currency for each country and the final column states the abbreviations that we use in this paper. All the currency rates are taken as difference of natural log values. 
Table 1

Currency Description

Note: This table shows the selected Asian countries, their currency names and the abbreviation used in this study.

\begin{tabular}{lcc}
\hline Country & Currency Name & Currency Short Name \\
\hline Bangladesh & Bangladesh Taka & BDT \\
China & Chinese Yuan & CNH \\
Hongkong & Hongkong Dollar & HKD \\
Indonesia & Indonesia Rupiah & IND \\
India & India Rupee & INR \\
Japan & Japanese Yen & JPY \\
Nepal & Nepal Rupee & NPR \\
Malaysia & Malaysia Ringgit & RING \\
Pakistan & Pakistan Rupee & PKR \\
Philippine & Philippine Peso & PHP \\
Sri Lanka & Sri Lanka Rupee & LKR \\
Singapore & Singapore Dollar & SGD \\
South Korea & South Korea Won & KOR \\
Taiwan & Taiwan Dollar & TDO \\
Thailand & Thailand Baht & BAHT \\
Vietnam & Vietnamese Dong & VND \\
\hline
\end{tabular}

\section{EMPIRICAL RESULTS}

This section discloses the key results from our analysis.

First, we present a visual depiction of the 16 currencies using time series plots. Figure 1 shows the dynamics of exchange rates against the US dollar. An inspection of the data shows that exchange rates have changed over the sample period and there is an increasing trend for Bangladesh taka, Sri Lanka rupee, Pakistan rupee, Indian rupee, Indonesia rupiah and Vietnamese dong throughout their sample period. This is an indication that with respect to the base currency (US dollar) these currencies have depreciated.

Next, in order to get an idea of the correlation structure, we have tabulated the Pearon's correlation coefficients for raw data of the 16 currencies. Table 2 indicates this. Here, we consider any correlation value say $\mathrm{r},|\mathrm{r}| \geq 0.9$ as high correlation and those are highlighted in the table. It can be observed that there are 10 pairwise correlations over $|0.90|$, indicating that these pairs have a relationship. The highlighted correlation pairs involve currencies-India rupee, Singapore dollar, Indonesia rupiah, Pakistan Rupee, Nepal rupee, Japanese yen, Sri Lanka rupee, Taiwan dollar, and Vietnamese dong. The relevant pairs are (INR, IND), (JPY, IND), (SGD, TDO), (VND, IND), (VND, INR), (INR, PKR), (PKR, IND), (PKR, NPR), (PKR, VND), and (LKR, NPR) respectively. The lowest correlations are recorded from the two pairs, namely (VND, KOR) and (PKR, PHP), and correlation is 0 . The values of the correlation matrix indicate that some of the currencies are correlated and hence any impact or shock of one currency may affect the currencies that show high correlations. Thus, the currency exchange rates are integrated or connected. This inspires us to examine the dynamic spillover (shock response and resistant) behavior of these currencies. 
Figure 1

Time Series Plots

Time series plots of daily exchange rates of 16 currencies are plotted here. They are; the Bangladesh Taka (BDT), Chinese yuan (CNH), Hongkong dollar (HKD), Indonesia rupiah (IND), India rupee (INR), Japanese yen (JPY), Nepal Rupee (NPR), Malaysia ringgit (RING), Pakistan rupee (PKR), Philippine Peso (PHP), Sri Lanka rupee (LKR), Singapore dollar (SGD), South Korea won (KOR), Taiwan dollar (TDO), Thailand baht (BAHT), and Vietnamese Dong (VND) for the period 01 January 2010 to 31 December 2019.

BANGLADESH TAKA TO US \$
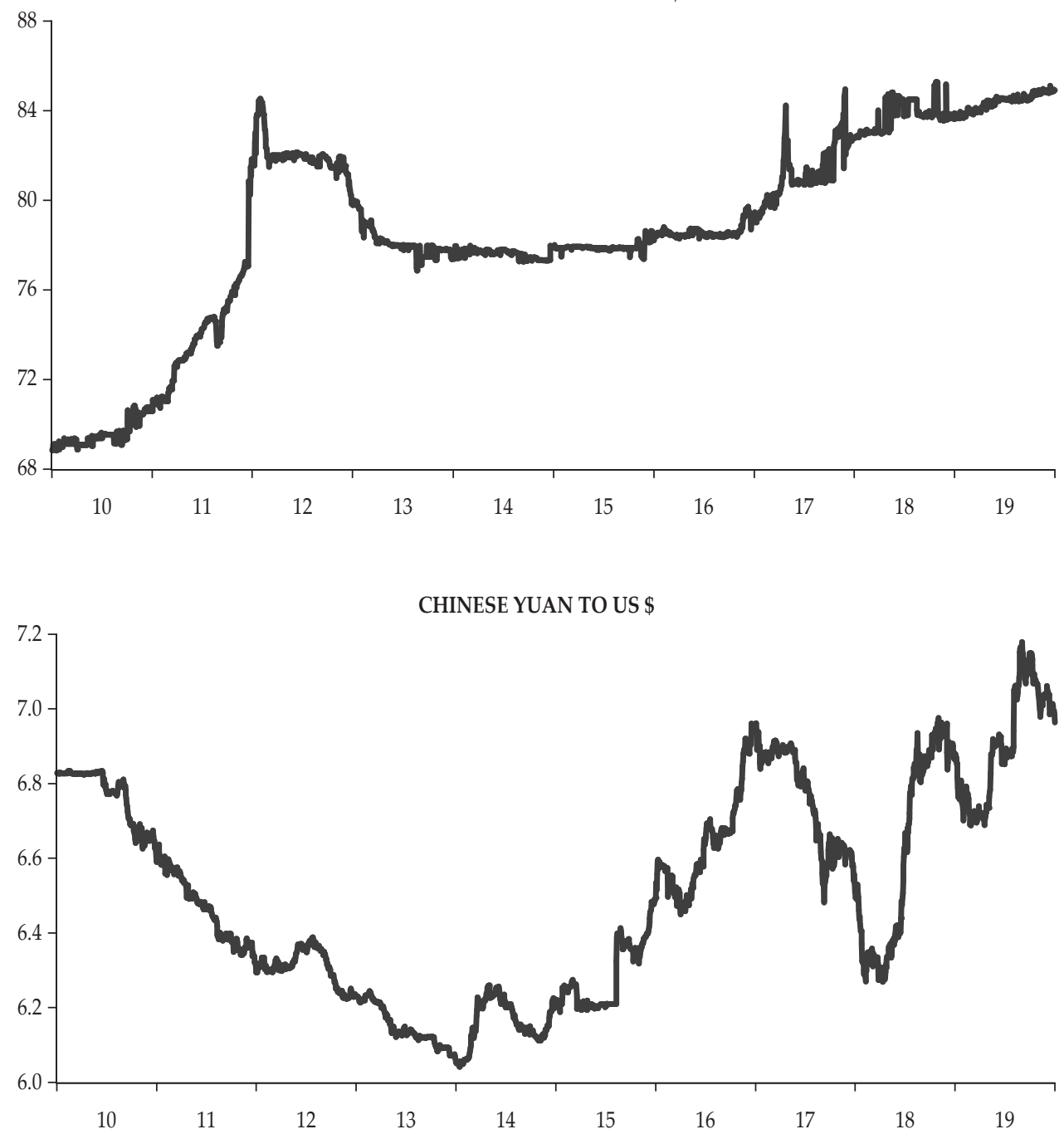
Figure 1

Time Series Plots (Continued)

HONG KONG \$ TO US \$

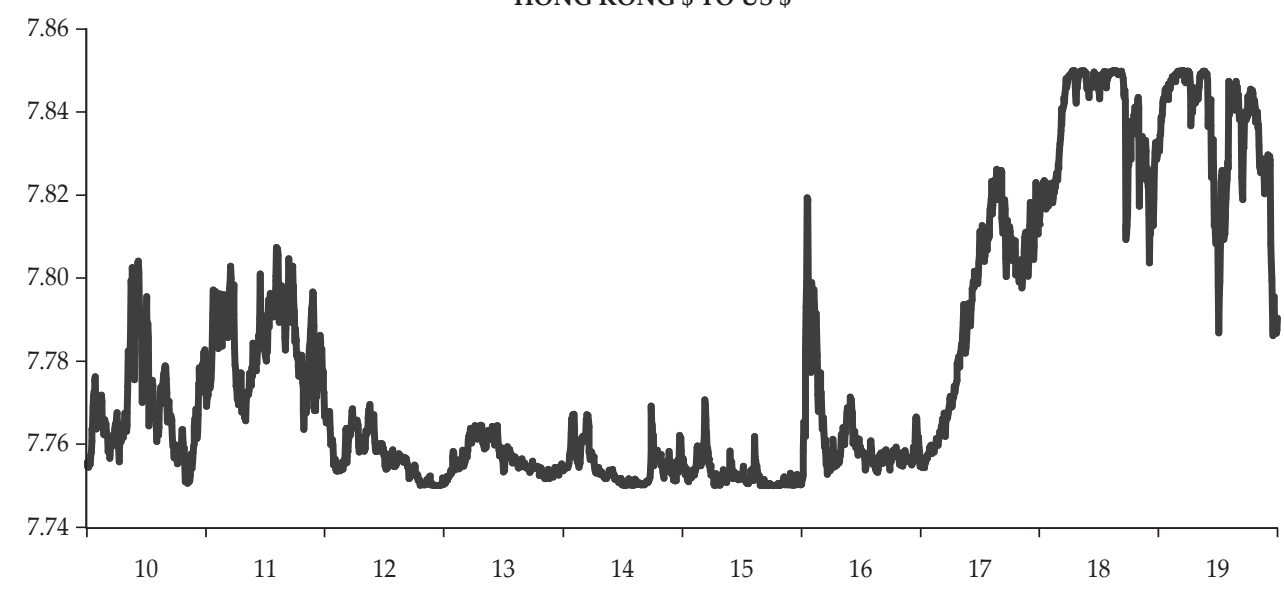

INDIAN RUPEE TO US \$

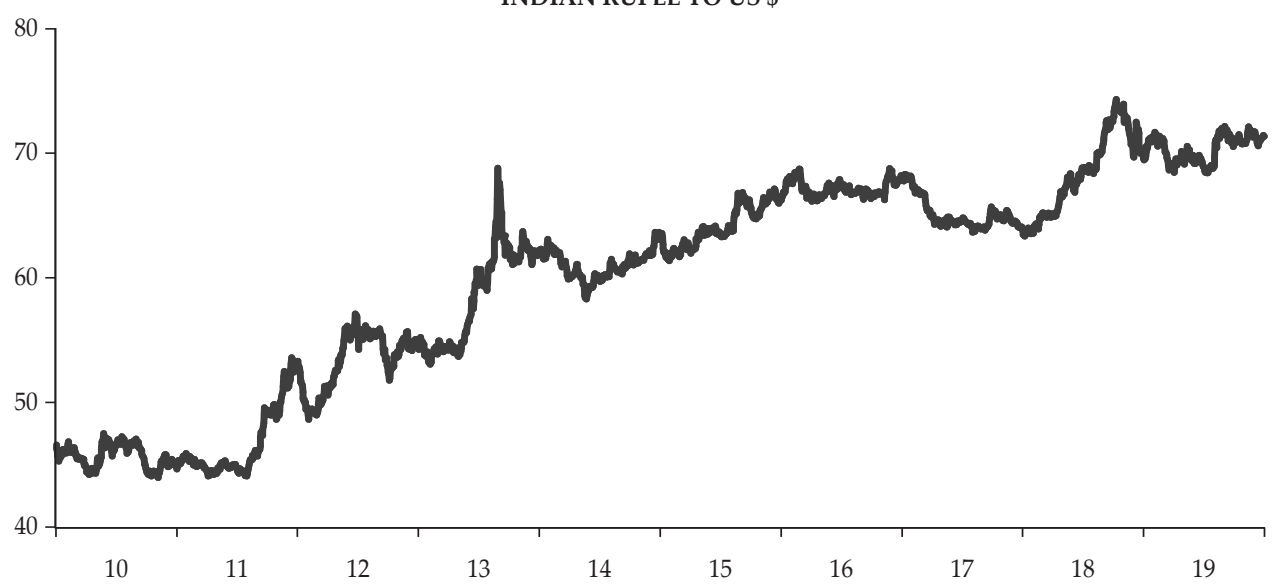

INDONESIAN RUPIAH TO US \$

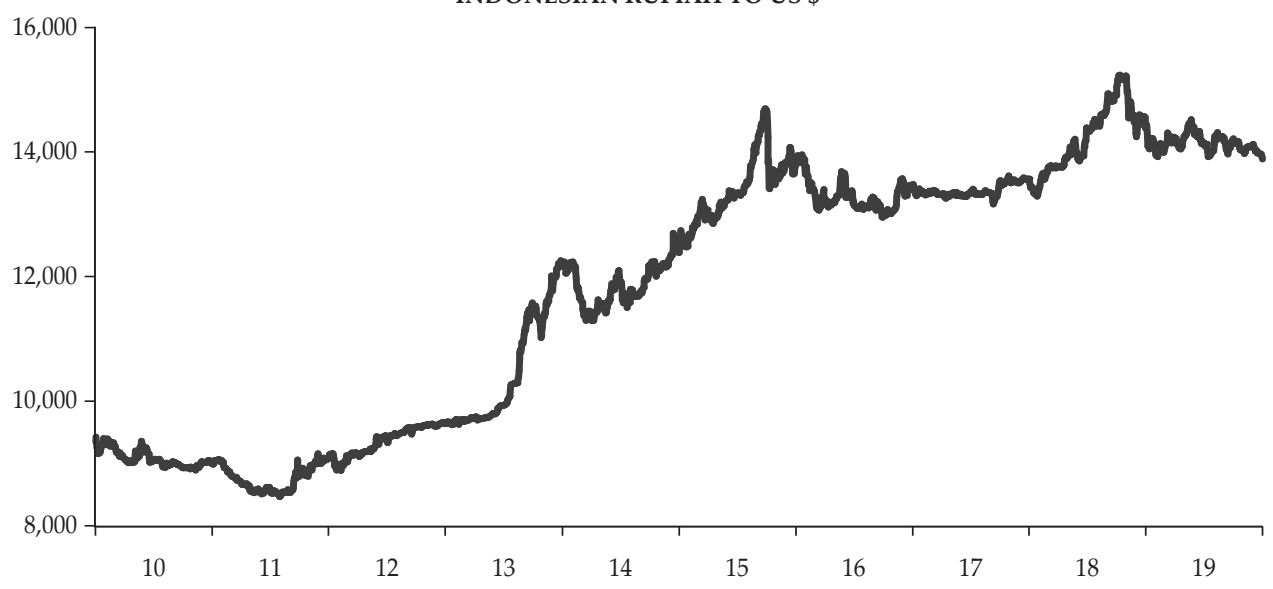


Figure 1

Time Series Plots (Continued)

JAPANESE YEN TO US \$
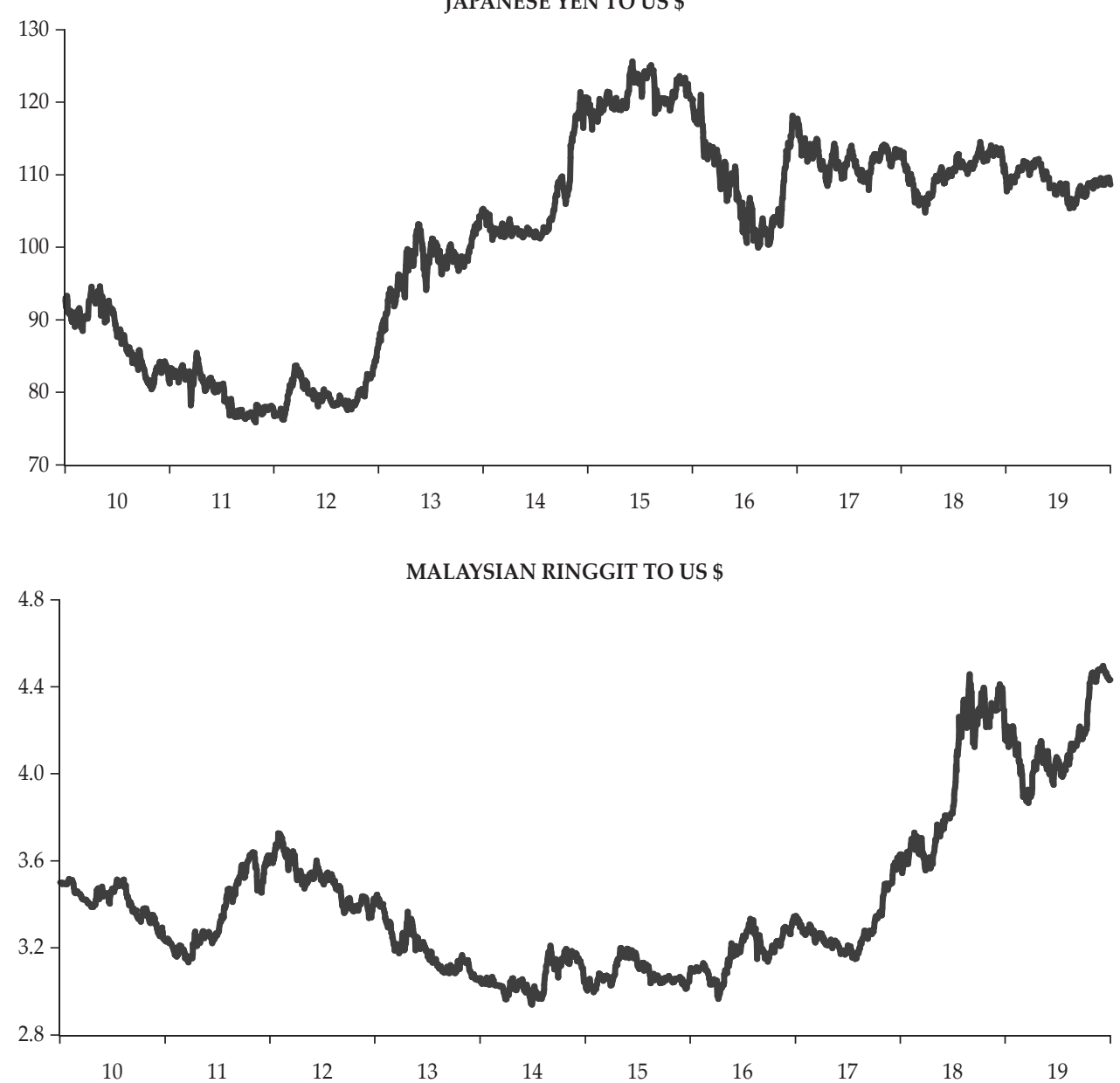

NEPAL RUPEE TO US \$

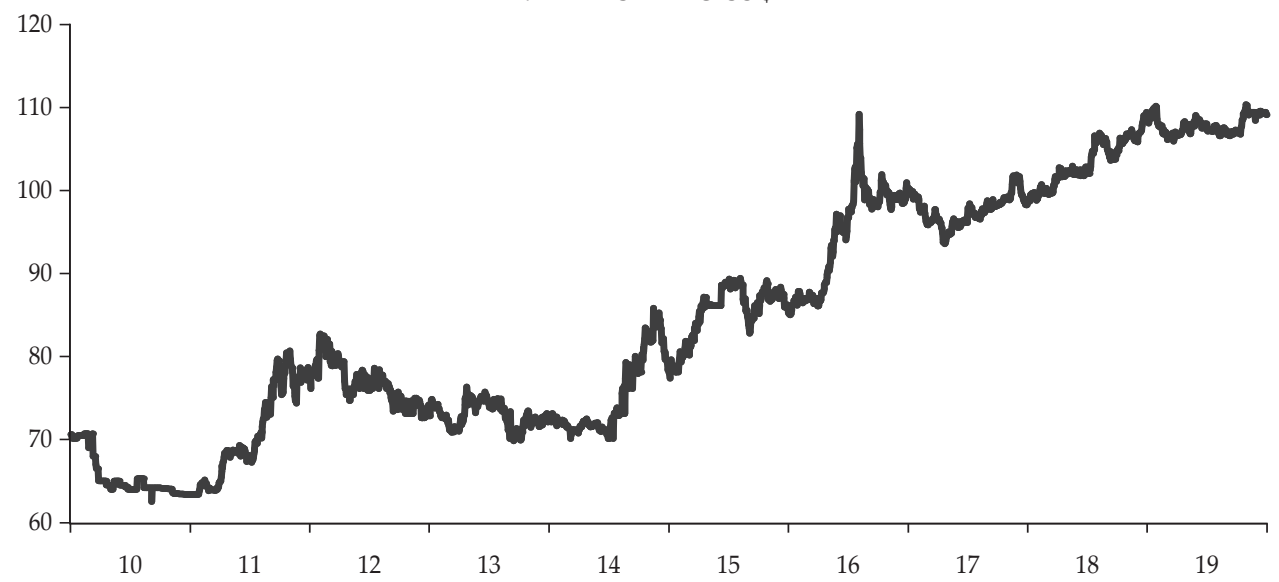


Figure 1

Time Series Plots (Continued)

PAKISTAN RUPEE TO US \$

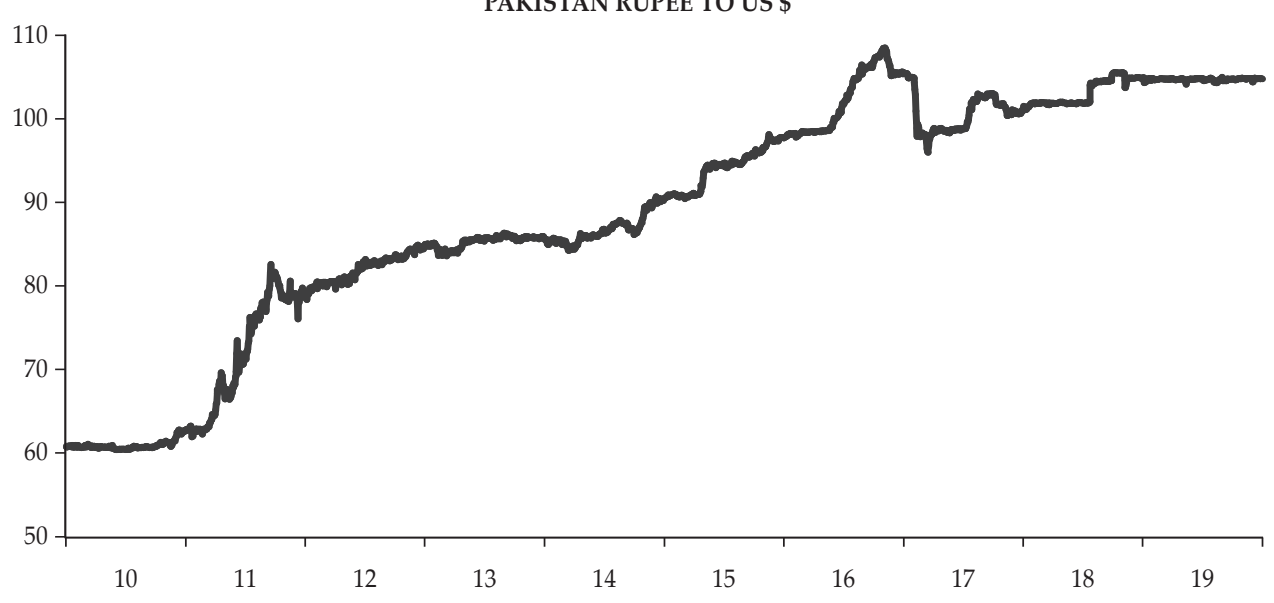

PHILIPPINE PESO TO US \$

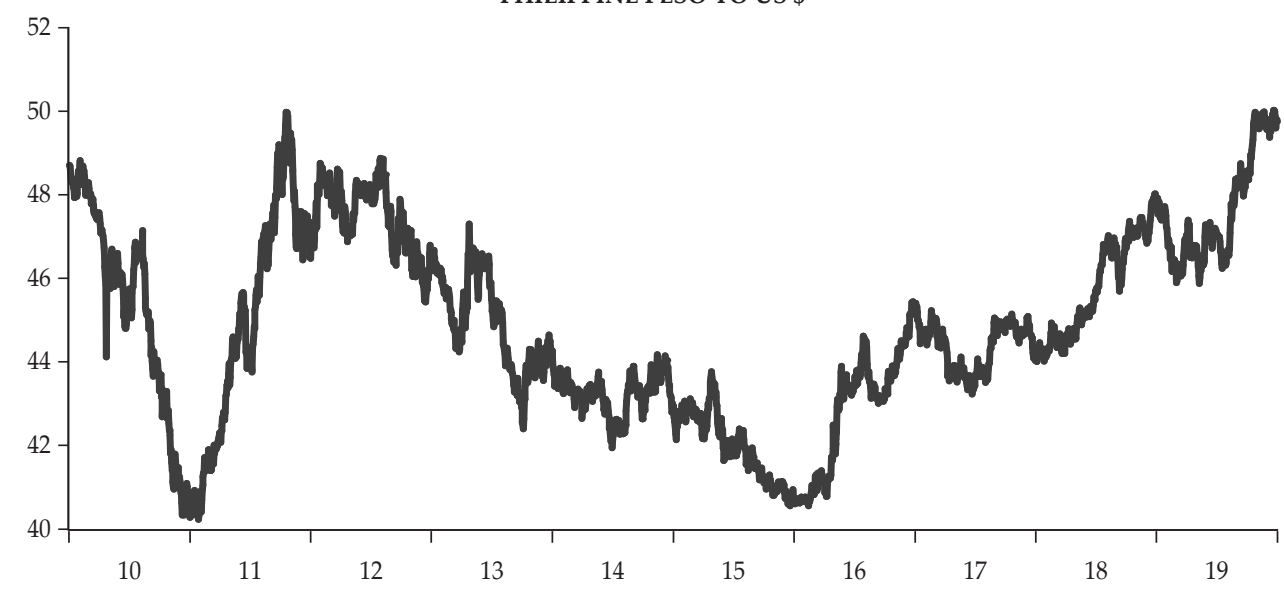

SINGAPORE \$ TO US \$

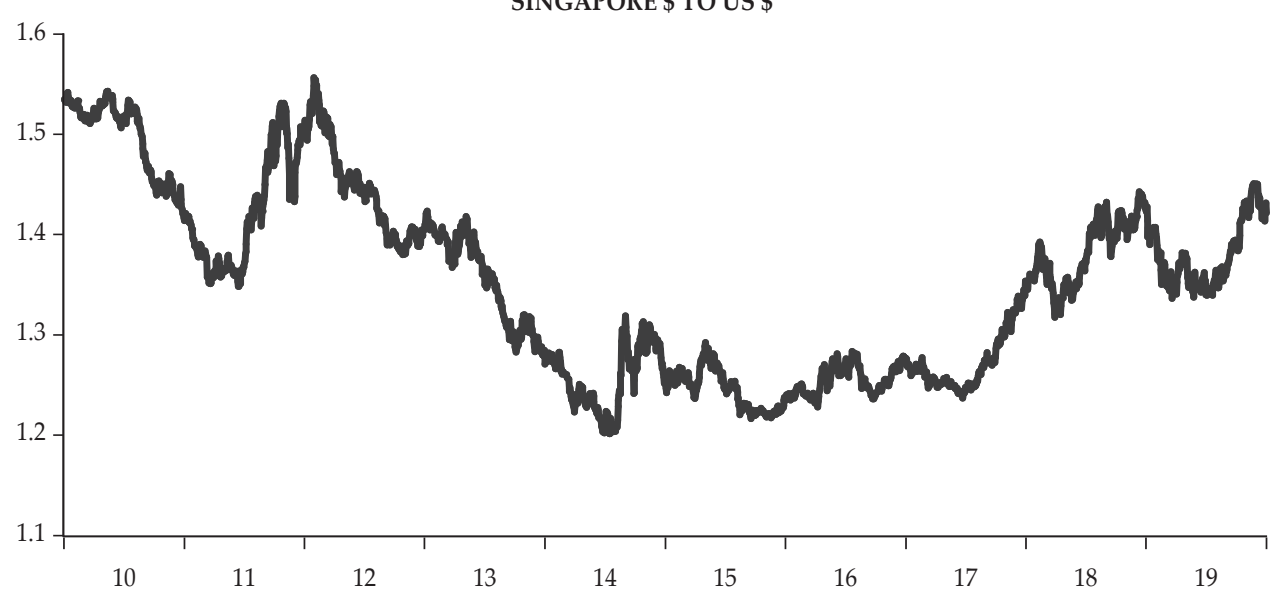


Figure 1

Time Series Plots (Continued)

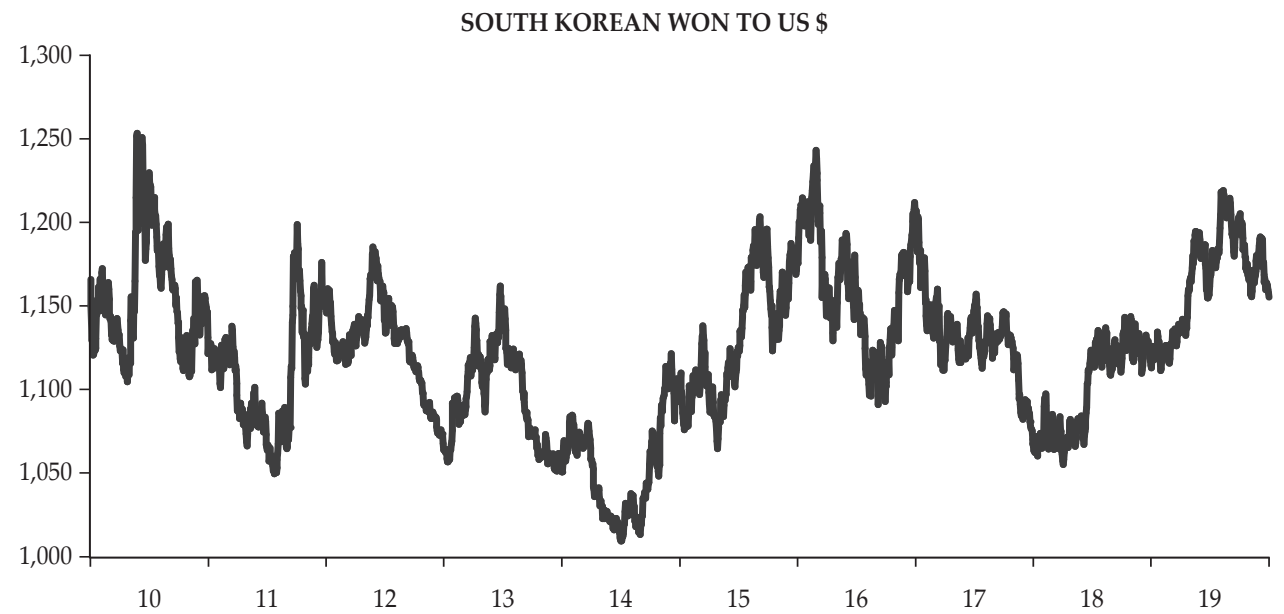

SRI LANKAN RUPEE TO US \$

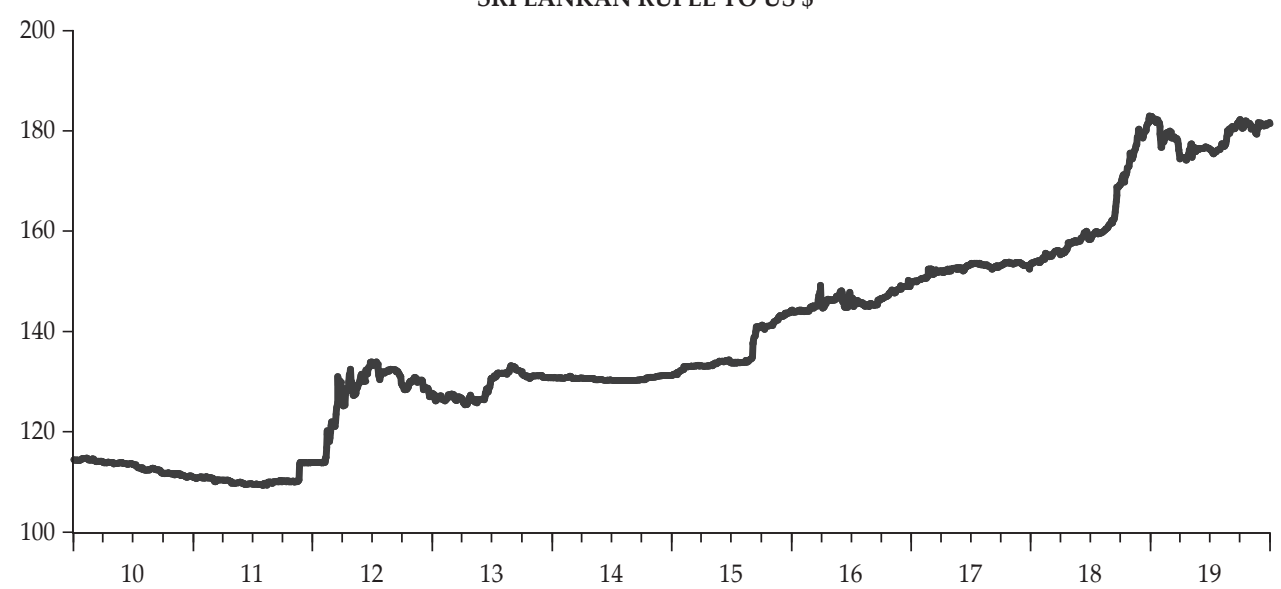

TAIWAN \$ TO US \$

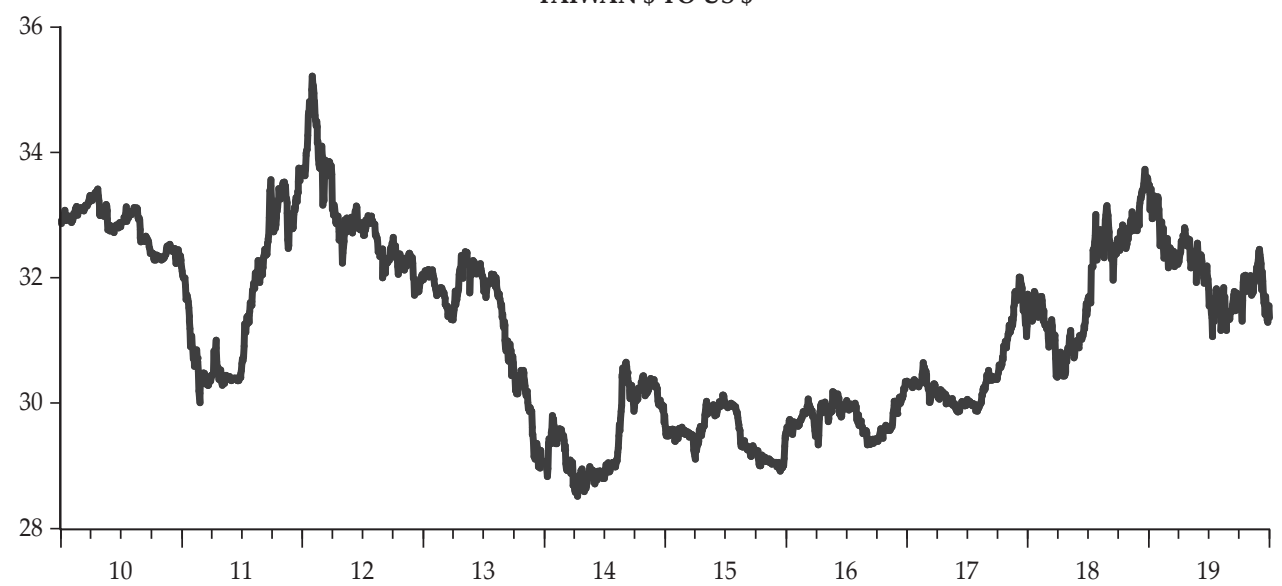


Figure 1

Time Series Plots (Continued)

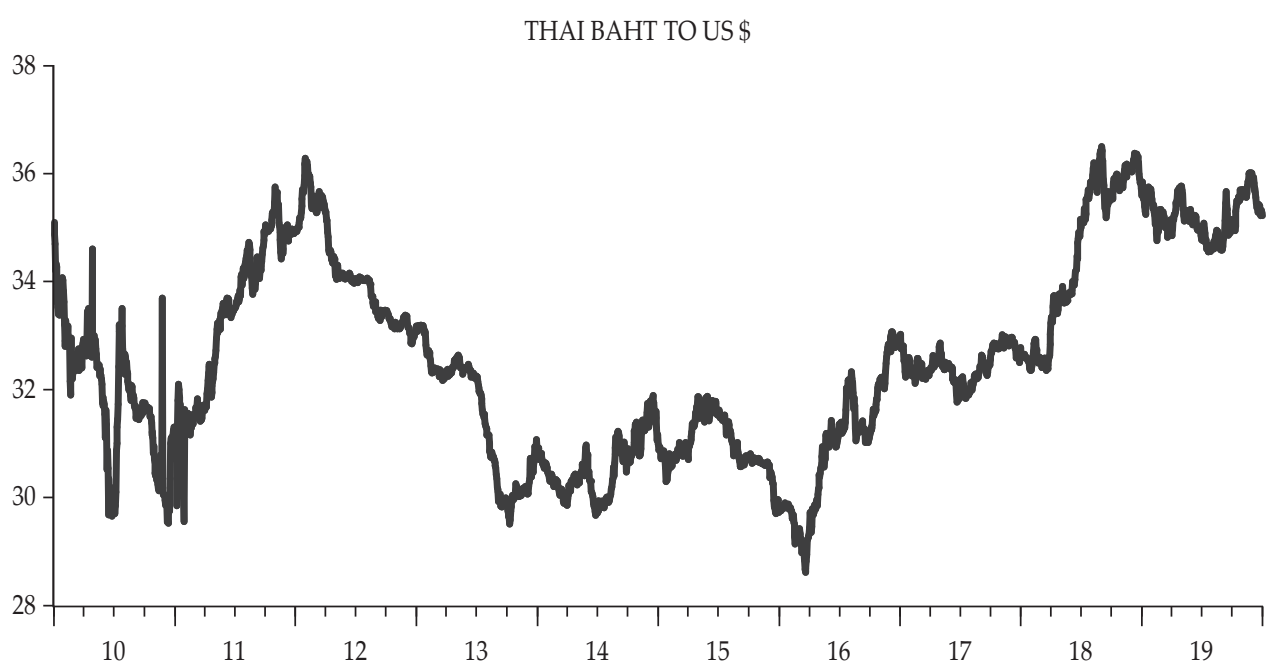

VIETNAMESE DONG TO US \$

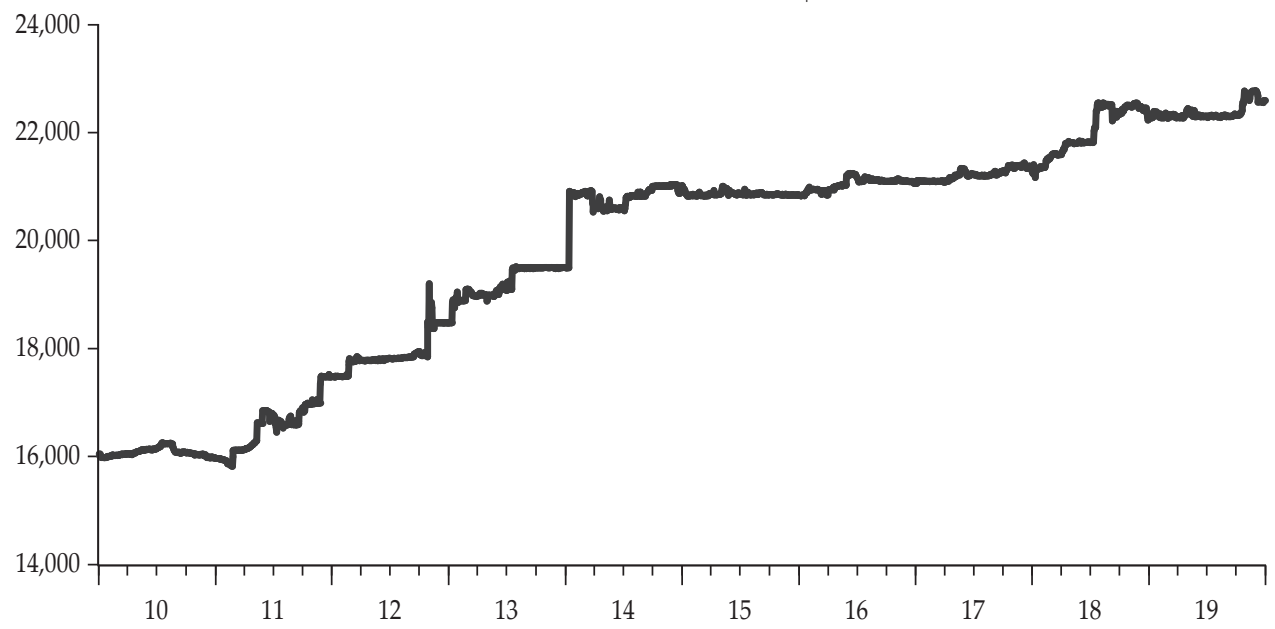




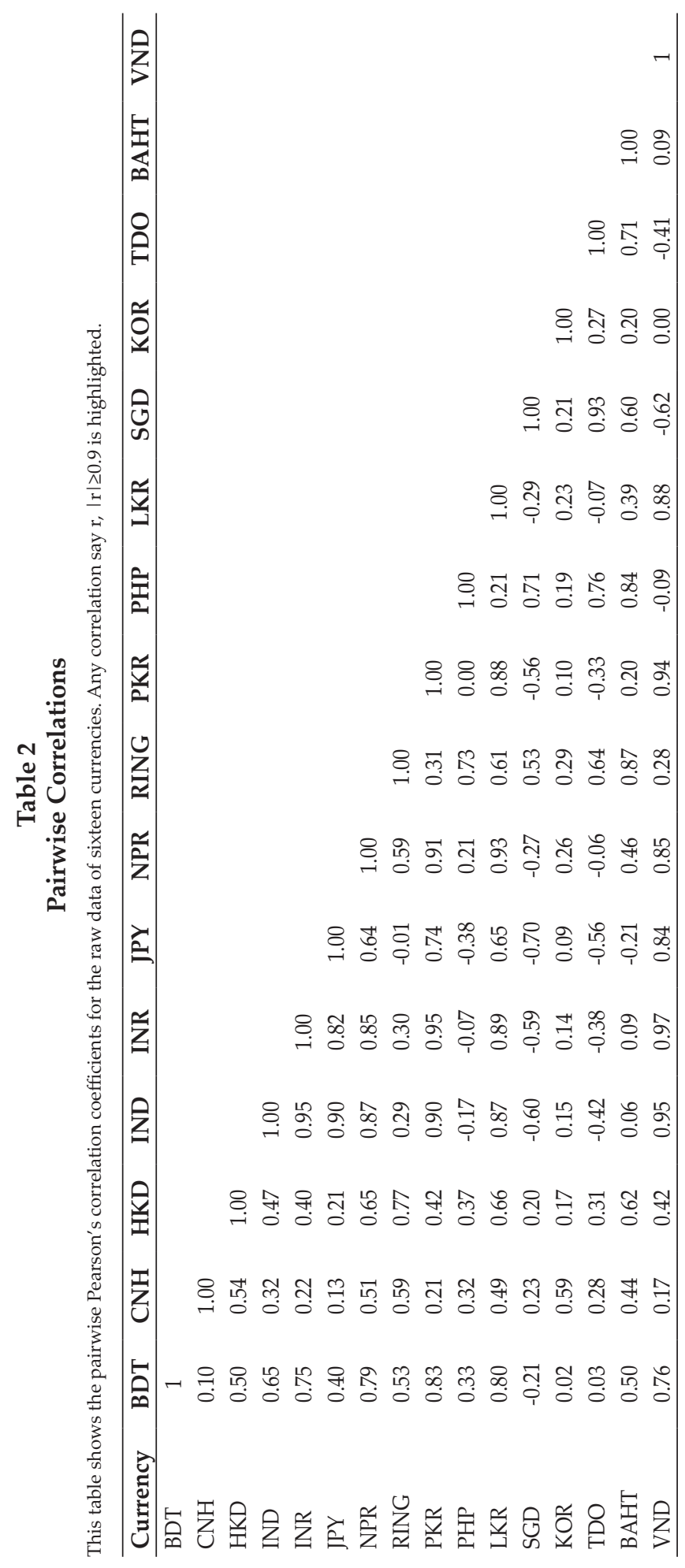




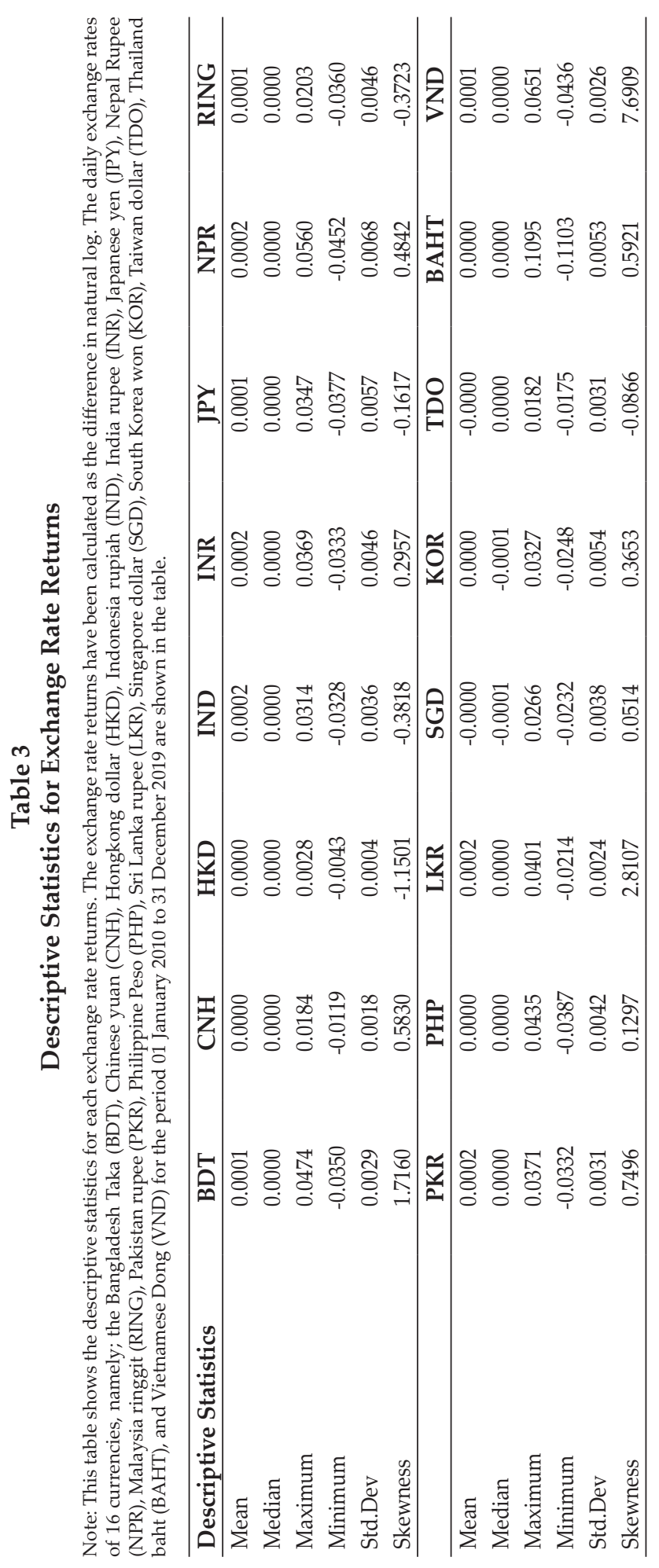




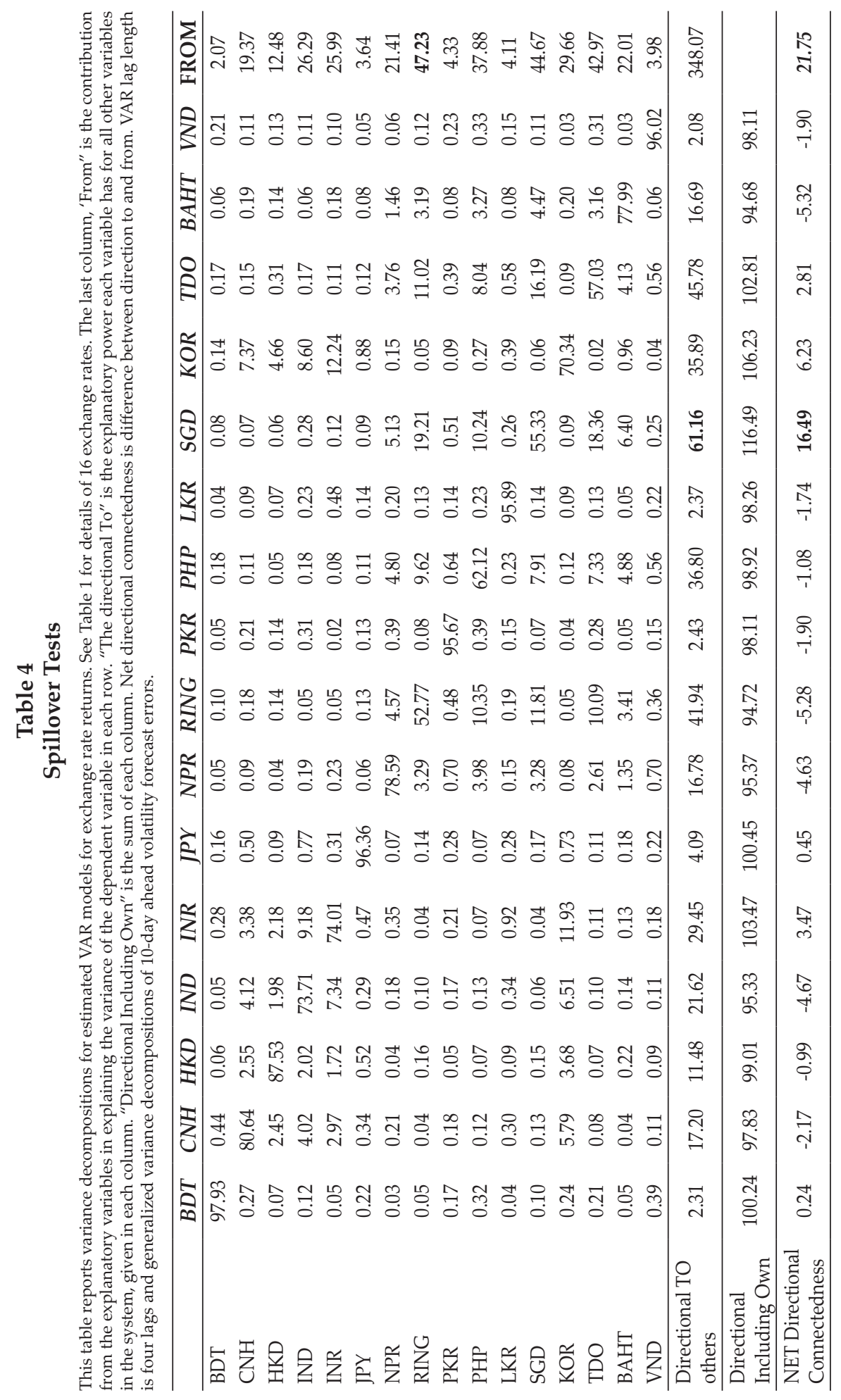


Table 3 shows descriptive statistics. We observe the highest mean of the exchange rate returns are for IND, INR, NPR, PKR, and LKR while the weakest currencies are SGD and TDO vis-à-vis the US dollar. We also notice that HKD is the least volatile currency while NPR is the most volatile. When we look at the shape of the data distribution, the skewness measure ranges from -1.1501 to 7.6909 for HKD and VND, respectively.

Table 4 reports the exchange rate return spillover results. In general, any entry $i j$ in the table is the estimated contribution to the forecast error variance of any one exchange rate return $i$ coming from innovations to exchange rate return $j$. Hence, the diagonal value of $97.93 \%$ of BDT shows the estimated contribution to the forecast error variance of the BDT return due to the innovations of their own return. The lowest diagonal value is reported by RING at $52.77 \%$. Thus, the own variance share is not equally strong for each country.

Now let us consider the directional spillover from column, which is the last column in Table 4. This column reveals the gross directional exchange rate return spillover from other exchange rate returns to each of them. Among these values, exchange rate return spillover from others to currency, RING, is recorded highest at $47.23 \%$. This is followed by SGD (44.67\%) and TDO (42.97\%). The spillover contribution from other currencies to BDT is the lowest at $2.07 \%$. By observing "directional to others" row, we notice the gross directional return spillovers to others from each of the sixteen currencies are different and are in the $2.08 \%$ to $61.16 \%$ range. The last row of the table shows the net directional return spillovers. Among them the largest spillover is coming from the Singapore dollar: SGD to others $(16.49 \%)$ and the lowest is from the currency BAHT $(-5.32 \%)$ to others. In column 3, innovations to the Chinese Yuan $(\mathrm{CNH})$ returns explain $2.45 \%$ of the error variance in forecasting 10-day-ahead Hong Kong Dollar (HKD) returns and $4.02 \%$ of the error variance in forecasting 10-day-ahead for Indonesia rupiah returns (IND). That is, return spillovers from the CNH to HKD are smaller.

In Table 4, we also have the total exchange return spillover index, which is $21.75 \%$ (it is computed as $348.21 / 1600^{*} 100$ ). This measures the contribution of return spillovers on 16 currencies to the total forecast error variance.

\section{CONCLUSION}

A growing integration of Asian countries over trade and investments is likely to have exchange rate shock spillover effects. If so, this information particular the currencies that influence others will be relevant for investors in portfolio diversification. This study explores the return effects of exchange rate spillovers for 16 Asian currencies.

We employ the spillover index proposed by Diebold and Yilmaz $(2009,2012)$ and use 10 years of daily exchange rate returns data to provide empirical evidence supporting spillover of exchange rate returns. The largest spillover is coming from the Singapore dollars to others (16.49\%). Overall, our results confirm the presence of exchange rate returns spillovers within the Asian countries and about $22 \%$ of the forecast error variance comes from the spillovers. 


\section{REFERENCES}

Al-Deehani, T., \& Moos, I.A. (2006). Volatility Spillover in Regional Emerging Stock Markets: A Structural Time-Series Approach. Emerging Markets Finance and Trade, 42, 78-89.

Baele, L. (2005). Volatility Spillover Effects in European Equity Markets, Journal of Financial and Quantitative Analysis, 40, 373-401.

Baillie, R.T., \& Bollerslev, T. (1991). Intra Day and Inter Day Volatility in Foreign Exchange Rates. Review of Economic Studies, 58, 565 -585.

Bubak, V., Kocenda, E., \& Zikes, F. (2011). Volatility Transmission in Emerging European Foreign Exchange Markets. Journal of Banking and Finance, 35, 2829 $-2841$.

Chow, H. K. (2017). Volatility Spillovers and Linkages in Asian Stock Markets. Emerging Markets Finance and Trade, 53, 2770 -2781.

Couderta, V., Couhardeb, C., \& Mignon, V. (2011). Exchange Rate Volatility across Financial Crises. Journal of Banking and Finance, 35, 3010 -3018.

Diebold, F.X., \& Yilmaz, K. (2009). Measuring financial Asset Return and Volatility Spillovers, With Application to Global Equity Markets. Economic Journal, 119, 1-14.

Diebold, F.X., \& Yilmaz, K. (2012). Better to Give Than to Receive: Predictive Directional Measurement of Volatility Spillovers. International Journal of forecasting, 28, 57-66.

Fukuda, S., \& Tanaka, M. (2017). The Impacts of Emerging Asia on Global Financial Markets. Emerging Markets Finance and Trade, 53, 2725-2743.

Kim J. S., \& Ryu, D. (2015) Return and Volatility Spillovers and Cojump Behavior between the U.S. and Korean Stock Markets. Emerging Markets Finance and Trade, 51, 3-17.

Kitamura, Y. (2010). Testing for Intraday Interdependence and Volatility Spillover among the Euro, the Pound and the Swiss Franc Markets. Research in International Business and Finance, 24, 158-171.

McMillan, D.G., \& Speigh, A.E.H. (2010). Return and Volatility Spillovers in Three Euro Exchange Rates. Journal of Economics and Business 62, 79-93.

Nguyen, M.K., \& Le, D.N. (2018). Return Spillover from the US and Japanese Stock Markets to the Vietnamese Stock Market: A Frequency-Domain Approach. Emerging Markets Finance and Trade. https://doi.org/10.1080/1540496X.2018.1525357 
This page is intentionally left blank 